\title{
Pulmonary fibrosis on multidetector computed tomography and mortality in patients with radiation-associated cardiac disease undergoing cardiac surgery
}

\author{
Milind Y. Desai, MD, ${ }^{\mathrm{a}, \mathrm{b}}$ Karuppasamy Karunakaravel, MD, ${ }^{\mathrm{b}}$ Willis Wu, MD, ${ }^{\mathrm{a}}$ Shikhar Agarwal, MD, ${ }^{\mathrm{a}}$ \\ Nicholas G. Smedira, MD, ${ }^{\mathrm{a}}$ Bruce W. Lytle, MD, ${ }^{\mathrm{a}}$ and Brian P. Griffin, MD ${ }^{\mathrm{a}}$
}

\begin{abstract}
Objective: In the long-term, malignancy-associated thoracic radiation leads to varying degrees of pulmonary fibrosis and radiation-associated cardiac disease, often requiring cardiothoracic surgery. We sought to determine whether pulmonary fibrosis affects mortality in patients with radiation-associated cardiac disease undergoing cardiothoracic surgery.
\end{abstract}

\begin{abstract}
Methods: We studied 117 patients (aged $63 \pm 15$ years, 71\% were women) with radiation-associated cardiac disease receiving multimodality imaging who underwent cardiothoracic surgery ( $21 \%$ redo) between 2000 and 2003. Some $50 \%$ of patients had breast cancer, $28 \%$ of patients had Hodgkin's lymphoma, $9 \%$ of patients had lung cancer, and $13 \%$ of patients had other cancers. Time from radiation was $18 \pm 12$ years. Clinical, pulmonary function, angiographic, and echocardiographic parameters were recorded. On multidetector chest computed tomography, ascending aortic calcification and degree of pulmonary fibrosis (in 5 lobes for a score of 15: $0=$ none, $1=$ linear streaks, $2=$ moderate fibrosis, and $3=$ severe fibrosis with traction bronchiectasis) were recorded.
\end{abstract}

Results: Mean European System for Cardiac Operative Risk Evaluation was $7.9 \pm 3$, and forced expiratory volume at 1 minute/forced vital capacity ratio was $0.75 \pm 0.2$. Mean left ventricular ejection fraction was $49 \% \pm 12 \%$, and right systolic ventricular pressure was $42 \pm 5 \mathrm{~mm} \mathrm{Hg}$. Some $27 \%$ of patients had severe aortic stenosis, and $46 \%$ of patients had II+ or greater mitral regurgitation. On multidetector chest computed tomography, mean pulmonary fibrosis score was $3.5 \pm 3$, and $59 \%$ of patients had ascending aortic calcification. Isolated coronary artery bypass was performed in $17 \%$ of patients; the rest were combination surgeries. At $6.3 \pm 0.4$ years, there were 59 deaths $(50 \%)$ (3\% died 1 month postoperatively). Forty-five patients $(39 \%)$ had pulmonary complications in follow-up. Increasing pulmonary fibrosis score (hazard ratio, 1.11; 95\% confidence interval, 1.02-1.20; $P=.02$ ), worse European System for Cardiac Operative Risk Evaluation (hazard ratio, 1.10; 95\% confidence interval, 1.01-1.21; $P=.04$ ), and lack of beta-blocker (hazard ratio, $0.54 ; 95 \%$ confidence interval, $0.31-0.94, P=.008$ ) and aspirin (hazard ratio, $0.54 ; 95 \%$ confidence interval, $0.31-0.94 ; P=.03$ ) independently predicted mortality.

Conclusions: In patients with radiation-associated cardiac disease undergoing cardiothoracic surgery, worsening pulmonary fibrosis is associated with increased mortality. (J Thorac Cardiovasc Surg 2014;148:475-81)

\section{Supplemental material is available online.}

Thoracic radiation is an effective treatment for mediastinal and thoracic cancers; however, cardiac disease is frequently observed as a major cause of morbidity and mortality in

\footnotetext{
From the Heart and Vascular Institute ${ }^{\mathrm{a}}$ and Imaging Institute, ${ }^{\mathrm{b}}$ Cleveland Clinic, Cleveland, Ohio.

Disclosures: Authors have nothing to disclose with regard to commercial support. Received for publication June 17, 2013; revisions received Aug 12, 2013; accepted for publication Aug 29, 2013; available ahead of print Nov 18, 2013.

Address for reprints: Milind Y. Desai, MD, Department of Cardiovascular Medicine,

Heart and Vascular Institute, Cleveland Clinic, 9500 Euclid Ave, Desk J1-5,

Cleveland, OH 44195 (E-mail: desaim2@ccf.org).

$0022-5223 / \$ 36.00$

Copyright (c) 2014 by The American Association for Thoracic Surgery

http://dx.doi.org/10.1016/j.jtcvs.2013.08.087
}

long-term survivors. ${ }^{1-6}$ Although the exact prevalence of radiation-associated cardiac disease (RACD) is difficult to ascertain, studies have suggested that up to $42 \%$ of patients will have significant asymptomatic valvular disease and $14 \%$ of patients will have myocardial ischemia ${ }^{1-3,7-11}$ in the next couple of decades after radiation. ${ }^{6}$ The prevalence of RACD is increasing because of maturation of the latent period from the initial administration of chest radiotherapy, which began in the late 1960s. The long-term cardiac effects of radiation seem to be fairly heterogeneous with aggressive coronary artery disease (especially ostial/proximal), valvular disease (including significant, especially anterior mitral annular thickening), pericardial disease (including diffuse calcific constriction), advanced diastolic dysfunction, and conduction disease developing in patients. ${ }^{7-11}$ These patients often require cardiothoracic surgery (CTS), and it is increasingly being recognized that such patients 


\begin{tabular}{|c|c|}
\hline \multicolumn{2}{|c|}{ Abbreviations and Acronyms } \\
\hline CABG & $=$ coronary artery bypass grafting \\
\hline CI & $=$ confidence interval \\
\hline CTS & $=$ cardiothoracic surgery \\
\hline euroSCC & $\begin{aligned}= & \text { European System for Cardiac } \\
& \text { Operative Risk Evaluation }\end{aligned}$ \\
\hline FEV1 & $=$ forced expiratory volume at 1 minute \\
\hline FVC & $=$ forced vital capacity \\
\hline $\mathrm{HR}$ & $=$ hazard ratio \\
\hline $\mathrm{LV}$ & $=$ left ventricular \\
\hline MDCT & $\begin{aligned} &= \text { multidetector chest computed } \\
& \text { tomography }\end{aligned}$ \\
\hline $\mathrm{PF}$ & $=$ pulmonary fibrosis \\
\hline RACD & $=$ radiation-associated cardiac disease \\
\hline VTI & $=$ velocity time integral \\
\hline
\end{tabular}

have a high degree of morbidity and mortality. ${ }^{2,3,5,12-15}$ In a recent large cohort study, we have demonstrated that patients with RACD have a significantly higher mortality compared with a similarly matched control population undergoing cardiac surgery. ${ }^{16}$ Furthermore, the primary cause of mortality in that study was cardiopulmonary failure during long-term follow-up.

In addition to peculiar echocardiographic features, ${ }^{16} \mathrm{a}$ characteristic pattern of pulmonary fibrosis (PF) also may develop in patients with prior thoracic radiation, ${ }^{17}$ ranging from linear fibrotic streaks to severe fibrosis and traction bronchiectasis, especially in the regions that are exposed to the radiation port (Figure E1). We sought to determine the impact of the severity of PF on long-term mortality in patients with RACD who underwent CTS.

\section{MATERIALS AND METHODS \\ Study Design}

This was an observational study of 117 consecutive patients with RACD who underwent CTS at the Heart and Vascular Institute and Imaging Institute between 2000 and 2003 and had a multidetector chest computed tomography (MDCT) scan and a resting echocardiogram performed in close temporal association with the cardiac surgery (typically within 1 month preoperatively). All patients had a history of malignancy requiring chest irradiation and as a result had subsequently developed coronary/ valvular disease requiring CTS. The diagnosis of RACD was made after a thorough clinical and echocardiographic evaluation by experienced cardiologists, based on characteristic findings, as described previously. ${ }^{16}$ In this group, type of prior malignancy and area of radiation were ascertained. Where available, year of last radiation dose was recorded. Also, the radiation dosages for various malignancies were recorded on the basis of historic data. All patients were cancer-free at the time of cardiac surgery.

\section{Clinical Data}

Data were assembled after appropriate approval by the institutional review board. Demographics and clinical data were recorded prospectively in the electronic health record. History and type of prior cardiac surgery were recorded. Use of medications at the time of initial presentation and whether they were initiated in the postoperative period were recorded. Presence of permanent atrial fibrillation (defined according to guidelines ${ }^{18}$ ) was ascertained at baseline and at the time of discharge. Presence of an automated implantable cardioverter defibrillator and need for permanent pacemaker were recorded. From spirometry and pulmonary function testing, we recorded forced vital capacity (FVC) and forced expiratory volume at 1 minute (FEV1) data. We calculated FEV1/FVC ratio. We also recorded the extent of any pulmonary complications during follow-up, dividing them as follows: simple (recurrent pleurocentesis, home oxygen use) and major (prolonged intubation with resultant tracheostomy and pleurodesis/decortication).

The details of cardiac surgery were recorded and categorized as follows: (1) coronary artery bypass grafting $(\mathrm{CABG})$; (2) $\mathrm{CABG}+1$-valve repair/ replacement; (3) CABG $+\geq 2$-valve repair/replacement; (4) 1-valve repair/replacement; (5) $\geq 2$-valve repair/replacement; and (6) others, including pericardiectomy, transplantation, left ventricular (LV) assist device, aortic surgery, and myectomy. In patients who underwent CABG, the number of bypassed vessels was recorded. On the basis of the available preoperative data, additive euroSCORE was calculated to predict the risk of postoperative mortality. ${ }^{19}$

\section{Follow-up}

The beginning of follow-up was considered as the date of cardiac surgery at our institution. Death notification was obtained from the medical record or the US Social Security Death Index database, and survival was ascertained during follow-up (last query was in March 2011). Where available, cause of death was ascertained. Postoperative stroke was defined as transient or permanent neurologic impairment and disability due to vascular causes, including episodes lasting less than 24 hours, which were regarded as transient ischemic attacks.

\section{Echocardiography}

All patients underwent a comprehensive transthoracic echocardiogram using commercial instruments (Philips Medical Systems, NA, Bothell, Wash; General Electric Medical Systems, Milwaukee, Wis; and Siemens Medical Solutions USA, Inc, Malvern, Pa) as part of standard clinical diagnostic and pre-open surgery workup. Standard parameters were assessed according to standard guidelines and recorded prospectively. ${ }^{20-23}$ Degree of mitral, aortic, and tricuspid regurgitation were assessed on a scale of 0 to $4+(0=$ none, $1+=$ mild, $2+=$ moderate, $3+=$ moderately severe, and $4+=$ severe). Right ventricular systolic pressure was recorded from tricuspid regurgitation velocity and estimated right atrial pressure. Peak/mean transvalvular gradients, velocity time integrals (VTIs) across valves/LV outflow tract, and diameter of LV outflow tract were recorded. Aortic valve area was calculated using continuity equation, and aortic stenosis was graded in a standard fashion. Dimensionless index (LV outflow tract VTI/aortic VTI) was calculated. Postoperative transthoracic echocardiography was performed as described earlier.

\section{Chest Multidetector Computed Tomography}

Cardiothoracic MDCT angiographic studies were performed using standard scanners available at the time (Siemens Medical Systems, Erlangen, Germany) using the following parameters: nongated spiral imaging, 750 to $850 \mathrm{mAs}, 120 \mathrm{kV}$, and 1-mm slice thickness. In 72 patients, at the discretion of the referring physicians, no iodinated contrast was administered. In the remaining 45 patients, $90 \mathrm{~mL}$ isosmolar contrast was administered, with use of peak enhancement in the aortic root for timing of the scan. Over the years, the scan parameters generally remained similar despite scanner upgrades. All images were acquired during an inspiratory breath hold of 10 to 20 seconds.

Two independent readers with experience in interpretation of chest computed tomography (MD and $\mathrm{KK}$ ) scored the degree of $\mathrm{PF}$, on a 


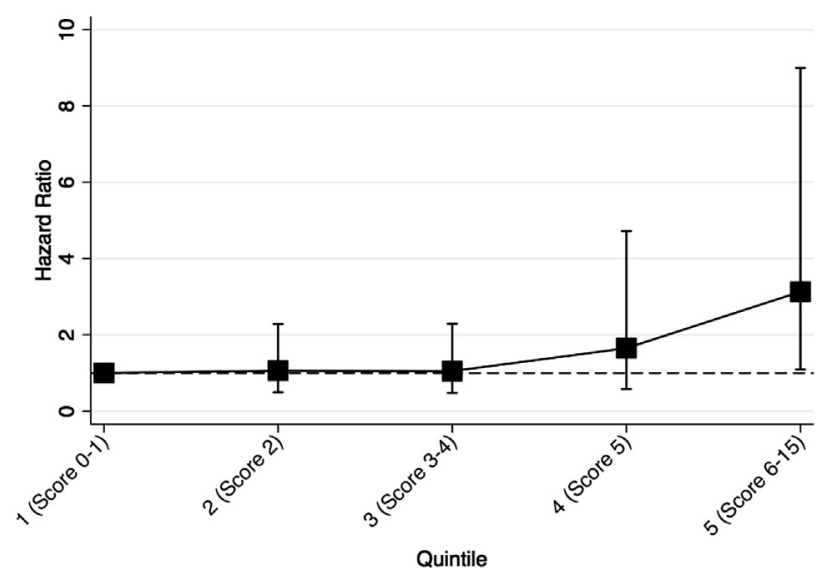

FIGURE 1. HRs for long-term mortality in patients with RACD plotted against mean PF score divided into 5 equal quintiles. All comparisons have been derived using Cox proportional hazard regression model using the first decile as the reference category.

semiquantitative scale (0-3) for each lobe of the lung, using an adaptation of previously published $\mathrm{x}$-ray criteria $^{17}$ : $0=$ none, $1=$ linear streaks, $2=$ moderate fibrosis, and $3=$ severe fibrosis with traction bronchiectasis (Figure E1). With the use of this scale, all 5 lobes of the lungs were scored, with a maximum score of 15 . The presence of ascending aortic calcification was ascertained and semiquantitatively scored as follows: none, mild (less than half of the circumference), moderate (half the circumference), and severe (more than half circumference). A detailed assessment of cardiac morphology (including coronaries and bypass grafts) was not the clinical focus; thus, the scans were not dedicated for their assessment. However, we did record the presence of high-risk features in patients undergoing redo cardiac surgery, as previously described: bypass grafts crossing midline less than $1 \mathrm{~cm}$ from the sternum, right-sided cardiac structures, and ascending aorta tethered to chest wall. ${ }^{24}$

\section{Statistical Analysis}

Continuous variables were expressed as mean \pm standard deviation or median. Categoric data are presented as percentage frequency. Differences between groups were compared with the use of the Student $t$ test or analysis of variance (for parametric variables) and the Mann-Whitney test (for nonparametric variables) for continuous variables. Chi-square test was used for categoric variables. Linear regression between continuous variables was tested using the Pearson correlation coefficient. Cumulative event rates as a function over time were obtained by the Kaplan-Meier method, and curves of mortality were compared using log-rank test. A univariable and multivariable Cox proportional hazards model was developed to determine the independent predictors of mortality. As a first step, univariable predictors were assessed individually using bootstrapping (to increase reliable assessment of risk factors by improving the precision of estimate), and a total of 1000 bootstrapped models were generated. Variables that entered the model at least 75 times were considered significant. Subsequently, stepwise multivariable regression analysis was performed, and the variables with a $P$ value less than .05 remained as independent predictors. The final univariate and multivariate results are represented by hazard ratios (HRs) and their $95 \%$ confidence intervals (CIs). To establish a cutoff above which the PF score was associated with a significant increase in mortality, we divided the score into quintiles. We subsequently conducted Cox survival analysis incorporating the PF score quintiles as an independent covariate. Statistical analysis was performed using SPSS version 11.5 (SPSS Inc, Chicago, Ill).
TABLE 1. Clinical characteristics of the study population

\begin{tabular}{|c|c|}
\hline Variable & $(\mathbf{n}=117)$ \\
\hline Age & $63 \pm 15 y$ \\
\hline Female gender & $83(71 \%)$ \\
\hline Hypertension & $48(41 \%)$ \\
\hline Diabetes mellitus & $19(16 \%)$ \\
\hline Prior stroke & $10(9 \%)$ \\
\hline Smoking history & $43(37 \%)$ \\
\hline Proximal obstructive coronary artery disease & $53(45 \%)$ \\
\hline Prior open surgery & $24(21 \%)$ \\
\hline Implantable cardioverter defibrillator & $7(6 \%)$ \\
\hline $\mathrm{FVC}(\mathrm{mL})$ & $2.1 \pm 0.9$ \\
\hline$\%$ predicted $\mathrm{FVC}$ & $66 \pm 22$ \\
\hline FEV1 & $1.6 \pm 0.6$ \\
\hline FEV1/FVC ratio & $0.75 \pm 0.2$ \\
\hline euroSCORE & $7.9 \pm 3$ \\
\hline Beta-blockers & $75(64 \%)$ \\
\hline ACE inhibitors & $42(36 \%)$ \\
\hline Aspirin & $64(55 \%)$ \\
\hline Statins & $38(32 \%)$ \\
\hline Hemoglobin (mg/dL) & $14 \pm 1.0$ \\
\hline Creatinine $(\mathrm{mg} / \mathrm{dL})$ & $0.98 \pm 0.5$ \\
\hline Total cholesterol & $179 \pm 44$ \\
\hline Low-density lipoprotein & $99 \pm 37$ \\
\hline Triglycerides & $144 \pm 85$ \\
\hline High-density lipoprotein & $52 \pm 17$ \\
\hline \multicolumn{2}{|l|}{ Type of CTS } \\
\hline CABG & $20(17 \%)$ \\
\hline $\mathrm{CABG}+1$ valve & $20(17 \%)$ \\
\hline $\mathrm{CABG}+\geq 2$ valve & $28(24 \%)$ \\
\hline 1 valve only & $22(19 \%)$ \\
\hline$\geq 2$ valves & $21(18 \%)$ \\
\hline Others & $6(5 \%)$ \\
\hline No. of bypass grafts & $1.3 \pm 1.4$ \\
\hline
\end{tabular}

$A C E$, Angiotensin-converting enzyme; $C A B G$, coronary artery bypass grafting; CTS, cardiothoracic surgery; euroSCORE, European System for Cardiac Operative Risk Evaluation; FEVI, forced expiratory volume at 1 minute; $F V C$, forced vital capacity.

\section{RESULTS}

\section{Clinical Characteristics}

The baseline characteristics of the study population are shown in Table 1 . This was a relatively young population with an average distribution of known cardiovascular risk factors. All patients had advanced symptoms necessitating cardiac surgery. No patient had advanced disease on pulmonary function testing to preclude surgery. In the group, 36 patients $(31 \%)$ had significant reduction in preoperative glomerular filtration rate $\left(<60 \mathrm{~mL} / \mathrm{min} / 1.73 \mathrm{~m}^{2}\right)$. The distribution of prior malignancies and average radiation doses were as follows: $59(50 \%)$ breast cancers (55 Gy), $9(8 \%)$ lung cancers (60 Gy), 33 (28\%) Hodgkin's lymphomas (45 gray), 6 (5\%) non-Hodgkin's lymphomas (45 Gy), and $10(9 \%)$ others (thymoma, testicular, and thyroid cancers, $45 \mathrm{~Gy}$ ). No patient had a known recurrence of malignancy at the time of cardiac surgery. The mean 
TABLE 2. Baseline imaging characteristics of the study population

\begin{tabular}{lc}
\hline \multicolumn{1}{c}{ Variable } & $\mathbf{N}=\mathbf{1 1 7}$ \\
\hline Preoperative echocardiography & \\
LV ejection fraction & $49 \% \pm 12 \%$ \\
LV end-diastolic dimension & $4.5 \pm 0.8 \mathrm{~cm}$ \\
LV end-systolic dimension & $3.2 \pm 1.0 \mathrm{~cm}$ \\
Left atrial dimension & $3.9 \pm 0.8 \mathrm{~cm}$ \\
Diastolic dysfunction & \\
Abnormal relaxation & $56(48 \%)$ \\
Pseudonormal & $16(14 \%)$ \\
Restrictive filling & $10(9 \%)$ \\
Mitral regurgitation $(\geq \mathrm{II}+)$ & $54(46 \%)$ \\
Mitral valve splitability score (of 16) & $5 \pm 4$ \\
Aortic regurgitation $(\geq \mathrm{II}+)$ & $41(35 \%)$ \\
Dimensionless index for aortic valve & $0.41 \pm 0.2$ \\
Severe aortic stenosis & $32(27 \%)$ \\
Tricuspid regurgitation $(\geq \mathrm{II}+)$ & $50(43 \%)$ \\
Right ventricular systolic pressure & $42 \pm 5 \mathrm{~mm} \mathrm{Hg}$ \\
Preoperative CT & \\
Moderate or more emphysema & 0 \\
PF score & $3.5 \pm 3$ \\
Ascending aortic calcification & $69(59 \%)$ \\
Ascending aortic calcification & \\
None & $48(41 \%)$ \\
Mild (<1/2 circumference) & $36(31 \%)$ \\
Moderate (1/2 circumference) & $18(15 \%)$ \\
Severe (circumferential) & $15(13 \%)$ \\
\hline$C T$, Computed tomography; $L V$, left ventricular $P F$, pulmonary fibrosis. \\
\end{tabular}

duration between current cardiac surgery and last chest radiation was $18 \pm 12$ years.

\section{Imaging Characteristics}

The baseline echocardiographic characteristics of the study population are shown in Table 2. In the study population, the distribution of LV ejection fraction was as follows: 69 patients $(59 \%)$ with ejection fraction $55 \%$ or greater, 36 patients $(31 \%)$ with ejection fraction between $30 \%$ and $55 \%$, and 12 patients $(10 \%)$ with ejection fraction less than 30\%. As shown in Table 2, there was a high prevalence of valvular heart disease.

MDCT characteristics are shown in Table 2. In the study population, 20 patients $(17 \%)$ had no evidence of $\mathrm{PF}$, and 35 patients $(30 \%)$ had a PF score of 1 or 2 (mild). The remainder had significant pulmonary fibrotic changes. There was a modest correlation between the PF score and the time of last chest radiation $(r=0.29, P<.01)$. There was no significant association between radiation dose and degree of PF in the study population $(r=0.10, P=$ not significant). As expected, there was an inverse correlation between PF score and FVC on pulmonary function testing $(r=-0.31, P<.01)$. There was only a modest correlation between European System for Cardiac Operative Risk Evaluation (euroSCORE) and PF score $(r=0.16$, $P=.07)$. The assessment of degree of PF in the study
TABLE 3. Stepwise multivariable Cox proportional hazard predictors of mortality in the study population

\begin{tabular}{lcc}
\hline \multicolumn{1}{c}{ Variable } & Hazard ratio $(\mathbf{9 5} \% \mathbf{C I})$ & $\boldsymbol{P}$ value \\
\hline Beta-blockers & $0.47(0.26-0.83)$ & .008 \\
Aspirin & $0.54(0.31-0.94)$ & .03 \\
euroSCORE & $1.10(1.01-1.21)$ & .04 \\
PF score on MDCT & $1.11(1.02-1.20)$ & .02 \\
\hline
\end{tabular}

Overall chi-square of the model: $27, P<.001$. Because age and creatinine are part of the euroSCORE, they were not included in the final multivariable analysis. Dimensionless index and FEV1/FVC ratio did not remain significant on stepwise multivariable analysis. CI, Confidence interval; euroSCORE, European System for Cardiac Operative Risk Evaluation; $M D C T$, multidetector chest computed tomography; $P F$, pulmonary fibrosis.

population had good interobserver and intraobserver reproducibility: Intraclass correlation coefficients were $0.90(0.76-0.96)$ and $0.92 \quad(0.81-0.96)$, respectively (both $P<.001$ ).

Ascending aortic calcification was noted in 69 patients $(60 \%)$, with $15(13 \%)$ having a porcelain aorta. The majority of patients with a history of redo cardiac surgery had tethering of right-sided cardiac structures to the chest wall (95\%), and 5 patients had CABG crossing midline less than $1 \mathrm{~cm}$ behind the sternum.

\section{Outcomes}

The clinical and echocardiographic results in the postoperative period for the entire study population are shown in Table E1. Relevant baseline and postoperative findings in the study population, divided according to high or low PF score, are shown in Table E2. As shown in Table E3, during a mean postoperative follow-up of $6.3 \pm 4$ years, a high proportion of patients in the study population had pulmonary complications $(39 \%$ with any and $19 \%$ with major complications). The proportion of patients with pulmonary complications was higher in the group with a PF score of 3 or greater versus the group with a PF score less than 3 (Table E2). This was despite similar euroSCORES: (1) any pulmonary complications versus no pulmonary complications $(8 \pm 3$ vs $7.8 \pm 3$, $P=.7)$ and (2) major pulmonary complications (7.6 \pm 4 vs $7.9 \pm 3, P=.7$ ). During follow-up, a high proportion of patients in the study population died $(n=59[50 \%])$. One-month mortality was low and occurred in only 4 patients $(3 \%)$. However, an additional 13 patients $(8 \%)$ died in the first year. The cause of death was ascertained to be cardiopulmonary disease in 55 patients $(49 \%)$ and recurrent malignancy in 5 patients $(5 \%)$. In the remaining patients, the cause of death could not be definitively ascertained. As expected, there was higher mortality in patients with pulmonary complications versus no pulmonary complications: any $(29[64 \%]$ vs $16[36 \%], P=.01)$ and major complications $(15[71 \%]$ vs $6[29 \%], P=.03)$.

Subsequently, we performed univariable and stepwise multivariable Cox proportional hazard analysis (Tables E3 and 3). 


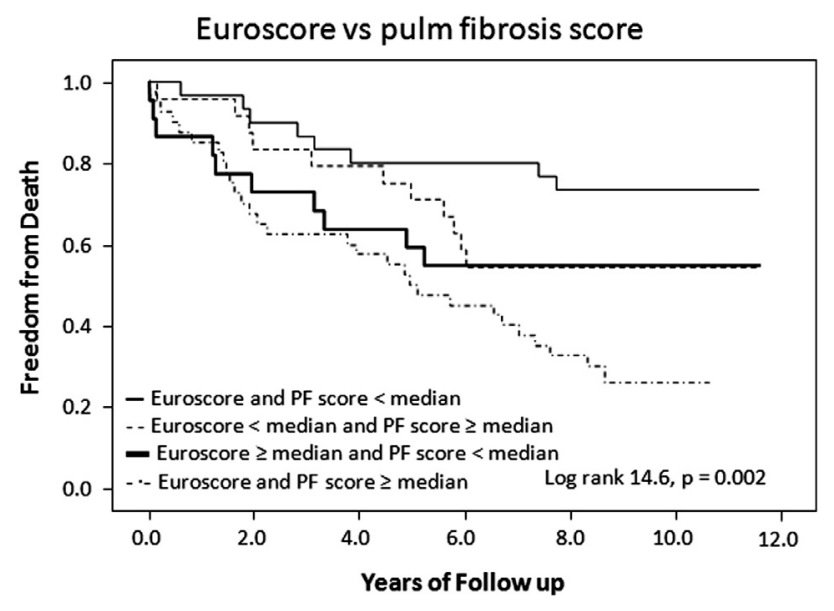

FIGURE 2. Kaplan-Meier curve analysis demonstrating significant differences in long-term mortality in patients with RACD, divided into 4 subgroups, based on medians of euroSCORE and PF score (see text for details). euroSCORE, European System for Cardiac Operative Risk Evaluation; $P F$, pulmonary fibrosis.

Worsening degree of PF, increasing euroSCORE, and lack of established cardioprotective medications (beta-blockers and aspirin) were associated with significantly reduced survival. Severity of aortic stenosis and lower FEV1/FVC ratio, although predicting worse mortality on univariable analysis, did not remain significant on stepwise multivariable analysis. In the subgroup undergoing redo CTS, no patient had injury to cardiac structures at the time of median sternotomy.

Medians of euroSCORE and PF score were generated, and Kaplan-Meier survival analysis was performed (Figures E2 and E3). On the basis of PF quintiles, we subsequently conducted Cox survival analysis incorporating it as an independent covariate. Figure $1 \mathrm{dem}-$ onstrates the HRs for mortality plotted against mean PF score within that quintile. All comparisons were derived using the first quintile as the reference category. It demonstrates that a PF score of 6 or greater was significantly predictive of mortality independently of euroSCORE, age, and gender. Finally, to understand the interplay between PF and euroSCORE, we further divided the patients into 4 subgroups as follows: (1) both below median $(\mathrm{n}=30)$; (2) PF score above median, euroSCORE below median $(\mathrm{n}=23)$; (3) PF score below median, euroSCORE above median $(\mathrm{n}=24)$; and $(4)$ both above median $(\mathrm{n}=40)$. During the follow-up, the distribution of mortality in these subgroups was $8(27 \%), 11(46 \%), 11$ $(48 \%)$, and $29(73 \%)$, respectively $(P<.001)$. The survival curves of these 4 subgroups are shown in Figure 2.

\section{DISCUSSION}

In the current study of patients with RACD who underwent complex CTS after a multimodality imaging evaluation (including MDCT and echocardiography), we demonstrate that increasing degree of $\mathrm{PF}$, assessed on preoperative MDCT, was a significant predictor of worse long-term mortality independently of euroSCORE. None of the standard echocardiographic variables independently predicted outcomes on multivariable survival analysis. Low dimensionless index (suggesting worse aortic stenosis) and FEV1/FVC ratio were associated with mortality on univariable analysis, but not on multivariable analysis. Although the degree or presence of ascending aortic calcification did not provide incremental predictive value for mortality, the stroke rate at 30 days was $0 \%$. In the current cohort of patients in whom MDCT was performed, requiring a redo cardiac procedure was not associated with increased mortality, with no reported bypass graft or cardiac structure injuries. This goes along with previous studies that have demonstrated the use of thoracic MDCT, before redo cardiac surgery, helps reduce postoperative complications. $^{24}$

As demonstrated previously, patients with RACD have a significantly higher mortality compared with an ageand gender-controlled population undergoing similar types of cardiac surgical procedures, despite similar euroSCORES. ${ }^{16}$ The majority of these patients died of cardiorespiratory causes, as opposed to recurrent malignancies. A high proportion of patients had residual pulmonary complications (including $18 \%$ requiring tracheostomy or pleurodesis/pleural decortication), and patients with pulmonary complications during follow-up were more likely to die. There was a significant association between PF, seen on preoperative MDCT, and postoperative pulmonary complications. Thus, there needs to be increased awareness of prior thoracic radiation, including characteristic pattern recognition on imaging studies. The current study also highlights that in RACD, prediction of mortality, solely based on standard preoperative scores, can be suboptimal. On the basis of the euroSCORE, the study population would have been deemed at intermediate risk with an expected mortality of approximately $3 \%$ to $5 \% .^{19,25}$ Thus, it seems that additional imaging evaluation, including assessment for pulmonary fibrotic changes on MDCT (Figure 2), is potentially useful and could provide incremental value in terms of risk prediction. For these complex patients, we need to develop a more appropriate diagnostic algorithm that incorporates findings on multimodality imaging.

Radiotherapy administered for thoracic malignancy results in a characteristic bimodal pattern of pulmonary damage: initial radiation pneumonitis (in $\sim 5 \%-15 \%$ cases) occurring early in the first 2 to 3 months, followed by PF, typically occurring after 3 months. ${ }^{26,27}$ Because MDCT scans in the current study were performed many years after chest radiotherapy, only PF changes were visualized. It has been shown that PF seldom occurs when the radiation dose is less than $20 \mathrm{~Gy}$, but highly likely when 
the dose is $60 \mathrm{~Gy}$ or more. ${ }^{26}$ In the current study, there was a modest but significant association between degree of $\mathrm{PF}$ and time from last radiation. PF occurs as a consequence of the repair process after acute tissue injury. ${ }^{28}$ Thoracic radiation and resultant PF can lead to symptoms due to reduction in FVC and diffusing capacity. ${ }^{29-31}$ A significantly higher proportion of patients with advanced $\mathrm{PF}$ had postoperative pulmonary complications and, in turn, increased mortality. It is conceivable that there is progressive pleural fibrosis and recurrent pleural effusions, both of which tend to be exacerbated further during cardiac surgery, resulting in additional deterioration of pulmonary function. Given these findings, it is important to anticipate and attempt to minimize these problems. On a preventive note, with increasing understanding of the deleterious long-term effects of radiotherapy for thoracic malignancies, every effort should be made to minimize exposure of the lungs and heart with the use of appropriate radiation shielding. However, in cases of some malignancies, such as Hodgkin's or non-Hodgkin's lymphoma, extensive mediastinal involvement might make cardiac shielding impossible. Previous studies also have evaluated the role of various medical therapies, including angiotensin-converting enzyme inhibitors and combined tocopherol/pentoxifylline in regression of radiation-induced fibrosis, with promising results. ${ }^{32,33}$ However, these findings need further validation in largescale human studies.

Previous reports have demonstrated various predictors of short-term mortality (constrictive pericarditis, reduced preoperative ejection fraction, longer cardiopulmonary bypass times) and long-term mortality (radiation dose, duration of radiation). ${ }^{1-3}$ However, these studies had significantly smaller sample sizes, and patients with complex surgeries (eg, CABG + valve procedures) were excluded. Chang and colleagues ${ }^{5}$ demonstrated that extensive radiation (as opposed to tangential exposure) was associated with worse survival. In all these studies, comprehensive multimodality imaging was not used. This is the largest study to systematically assess the incremental prognostic utility of multimodality imaging characteristics on long-term mortality in this high-risk population.

\section{Clinical Implications and Future Outlook}

From a management perspective, given the high complexity in patients with RACD, it seems appropriate to carefully characterize these patients using clinical (including detailed pulmonary function testing) and multimodality imaging (echocardiography and, in selected cases, MDCT). On the basis of the current study, it seems that a PF score of 6 or greater is associated with a significant increase in mortality. As a result, once a high-risk substrate has been identified, it might be prudent to examine other treatment options, such as percutaneous intervention for coronary artery disease or transcatheter aortic valve replacement. $^{34,35}$ Another consideration is heart transplantation or heart lung transplantation in selected patients. However, this approach has potentially significant additional issues, such as recurrent malignancy. In addition, the effect of radiation on the pulmonary vasculature and thoracic volume may render lung transplantation difficult or even impossible. In patients with documented $\mathrm{PF}$, strategies to reduce pulmonary damage during cardiac surgery should be incorporated. Further research in the field of optimizing lung function preoperatively (eg, preemptive pulmonary rehabilitation) is needed.

\section{Study Limitations}

This was an observational study with potential tertiarycare referral bias; thus, the data are not generalizable to all patients with a history of thoracic radiation. Because the majority of these patients were referred long after their initial cancer diagnosis, comprehensive data on radiation dose and chemotherapeutic regimen (especially doxorubicin [Adriamycin; Bedford Laboratories, Bedford, Ohio]/bleomycin, which could affect PF) were not available. However, we did incorporate radiation doses that were prevalent at the time of their initial cancer diagnosis into our analysis. During the time frame that the patients with RACD were evaluated and underwent operation at our institution, performing MDCT was not a clinical routine. As a result, the sample size of patients undergoing a complete multimodality imaging evaluation was smaller than those with RACD undergoing surgery. Semiquantitative PF assessment by MDCT is not standardized. Comprehensive pulmonary function testing data (especially diffusing capacity) were not always performed and thus are not reported. Advanced echocardiography indices, including tissue Doppler and strain analysis, was not available at the time of surgery. Data on cancer recurrence during post-radiotherapy follow-up (at the site of radiation or a remote site) were not uniformly available. However, all patients were free of malignancy at the time of cardiac surgery. Cardiopulmonary bypass times were not available as part of electronic health records; however, it is conceivable that they were higher in these high-risk complex cases. We chose all-cause mortality because it is more relevant in the current population.

\section{CONCLUSIONS}

Worsening degree of PF in patients with RACD undergoing CTS is associated with significantly worse long-term outcomes independently of standard preoperative risk stratification. A dedicated multifaceted diagnostic approach (including echocardiography, chest MDCT, and pulmonary function testing) should be adopted to carefully evaluate these patients preoperatively. Once a high-risk substrate is identified, alternative treatment options might be worth 
exploring. However, further research is needed in these high-risk patients.

\section{References}

1. Hancock SL, Tucker MA, Hoppe RT. Factors affecting late mortality from heart disease after treatment of Hodgkin's disease. JAMA. 1993;270:1949-55.

2. Handa N, McGregor CG, Danielson GK, Daly RC, Dearani JA, Mullany CJ, et al. Valvular heart operation in patients with previous mediastinal radiation therapy. Ann Thorac Surg. 2001;71:1880-4.

3. Handa N, McGregor CG, Danielson GK, Orszulak TA, Mullany CJ, Daly RC, et al. Coronary artery bypass grafting in patients with previous mediastinal radiation therapy. J Thorac Cardiovasc Surg. 1999;117:1136-42.

4. Nishimura RA, Carabello BA, Faxon DP, Freed MD, Lytle BW, O'Gara PT, et al, ACC/AHA 2008 guideline update on valvular heart disease: focused update on infective endocarditis: a report of the American College of Cardiology/American Heart Association Task Force on Practice Guidelines: endorsed by the Society of Cardiovascular Anesthesiologists, Society for Cardiovascular Angiography and Interventions, and Society of Thoracic Surgeons. Circulation. 2008;118: 887-96.

5. Chang AS, Smedira NG, Chang CL, Benavides MM, Myhre U, Feng J, et al. Cardiac surgery after mediastinal radiation: extent of exposure influences outcome. J Thorac Cardiovasc Surg. 2007;133:404-13.

6. Glanzmann C, Kaufmann P, Jenni R, Hess OM, Huguenin P. Cardiac risk after mediastinal irradiation for Hodgkin's disease. Radiother Oncol. 1998;46:51-62.

7. Adams MJ, Lipshultz SE, Schwartz C, Fajardo LF, Coen V, Constine LS. Radiation-associated cardiovascular disease: manifestations and management. Semin Radiat Oncol. 2003;13:346-56.

8. Arsenian MA. Cardiovascular sequelae of therapeutic thoracic radiation. Prog Cardiovasc Dis. 1991;33:299-311.

9. Heidenreich PA, Hancock SL, Lee BK, Mariscal CS, Schnittger I. Asymptomatic cardiac disease following mediastinal irradiation. J Am Coll Cardiol. 2003;42:743-9.

10. Lee PJ, Mallik R. Cardiovascular effects of radiation therapy: practical approach to radiation therapy-induced heart disease. Cardiol Rev. 2005;13:80-6.

11. Veinot JP, Edwards WD. Pathology of radiation-induced heart disease: a surgical and autopsy study of 27 cases. Hum Pathol. 1996;27:766-73.

12. Crestanello JA, McGregor CG, Danielson GK, Daly RC, Dearani JA, Orszulak TA, et al. Mitral and tricuspid valve repair in patients with previous mediastinal radiation therapy. Ann Thorac Surg. 2004;78:826-31.

13. Reber D, Birnbaum DE, Tollenaere P. Heart diseases following mediastinal irradiation: surgical management. Eur J Cardiothorac Surg. 1995;9:202-5.

14. Veeragandham RS, Goldin MD. Surgical management of radiation-induced heart disease. Ann Thorac Surg. 1998;65:1014-9.

15. Hicks GL Jr. Coronary artery operation in radiation-associated atherosclerosis: long-term follow-up. Ann Thorac Surg. 1992;53:670-4.

16. Wu W, Masri A, Popovic ZB, Smedira NG, Lytle B, Marwick TH, et al. Long-term survival of patients with radiation heart disease undergoing cardiac surgery: a cohort study. Circulation. 2013;127:1476-85.

17. Arriagada R, de Guevara JC, Mouriesse H, Hanzen C, Couanet D, Ruffie P, et al. Limited small cell lung cancer treated by combined radiotherapy and chemotherapy: evaluation of a grading system of lung fibrosis. Radiother Oncol. $1989 ; 14: 1-8$.

18. Fuster V, Ryden LE, Cannom DS, Crijns HJ, Curtis AB, Ellenbogen KA, et al. ACC/AHA/ESC 2006 Guidelines for the Management of Patients with Atrial Fibrillation: a report of the American College of Cardiology/American Heart Association Task Force on Practice Guidelines and the European Society of Cardiology Committee for Practice Guidelines (Writing Committee to Revise the 2001 Guidelines for the Management of Patients With Atrial Fibrillation): developed in collaboration with the European Heart Rhythm Association and the Heart Rhythm Society. Circulation. 2006;114:e257-354.

19. Nashef SA, Roques F, Michel P, Gauducheau E, Lemeshow S, Salamon R. European system for cardiac operative risk evaluation (EuroSCORE). Eur J Cardiothorac Surg. 1999;16:9-13.
20. Lang RM, Bierig M, Devereux RB, Flachskampf FA, Foster E, Pellikka PA, et al Recommendations for chamber quantification: a report from the American Society of Echocardiography's Guidelines and Standards Committee and the Chamber Quantification Writing Group, developed in conjunction with the European Association of Echocardiography, a branch of the European Society of Cardiology. J Am Soc Echocardiogr. 2005;18:1440-63.

21. Nagueh SF, Appleton CP, Gillebert TC, Marino PN, Oh JK, Smiseth OA, et al. Recommendations for the evaluation of left ventricular diastolic function by echocardiography. Eur J Echocardiogr. 2009;10:165-93.

22. Zoghbi WA, Enriquez-Sarano M, Foster E, Grayburn PA, Kraft CD, Levine RA et al. Recommendations for evaluation of the severity of native valvular regurgitation with two-dimensional and Doppler echocardiography. J Am Soc Echocardiogr. 2003;16:777-802.

23. Bonow RO, Carabello BA, Kanu C, de Leon AC Jr, Faxon DP, Freed MD, et al. ACC/AHA 2006 guidelines for the management of patients with valvular heart disease: a report of the American College of Cardiology/American Heart Association Task Force on Practice Guidelines (writing committee to revise the 1998 Guidelines for the Management of Patients With Valvular Heart Disease): developed in collaboration with the Society of Cardiovascular Anesthesiologists: endorsed by the Society for Cardiovascular Angiography and Interventions and the Society of Thoracic Surgeons. Circulation. 2006; 114:e84-231.

24. Kamdar AR, Meadows TA, Roselli EE, Gorodeski EZ, Curtin RJ, Sabik JF, et al. Multidetector computed tomographic angiography in planning of reoperative cardiothoracic surgery. Ann Thorac Surg. 2008;85:1239-45.

25. Higgins TL, Estafanous FG, Loop FD, Beck GJ, Blum JM, Paranandi L. Stratification of morbidity and mortality outcome by preoperative risk factors in coronary artery bypass patients. A clinical severity score. JAMA. 1992;267: 2344-8.

26. Abid SH, Malhotra V, Perry MC. Radiation-induced and chemotherapy-induced pulmonary injury. Curr Opin Oncol. 2001;13:242-8.

27. Carver JR, Shapiro CL, Ng A, Jacobs L, Schwartz C, Virgo KS, et al. American Society of Clinical Oncology clinical evidence review on the ongoing care of adult cancer survivors: cardiac and pulmonary late effects. J Clin Oncol. 2007; 25:3991-4008

28. Mazeron R, Etienne-Mastroianni B, Perol D, Arpin D, Vincent M, Falchero L, et al. Predictive factors of late radiation fibrosis: a prospective study in non-small cell lung cancer. Int J Radiat Oncol Biol Phys. 2010;77:38-43.

29. Horning SJ, Adhikari A, Rizk N, Hoppe RT, Olshen RA. Effect of treatmen for Hodgkin's disease on pulmonary function: results of a prospective study. J Clin Oncol. 1994;12:297-305.

30. Lund MB, Kongerud J, Nome O, Abrahamsen AF, Bjortuft O, Forfang K, et al Lung function impairment in long-term survivors of Hodgkin's disease. Ann Oncol. 1995;6:495-501.

31. Theuws JC, Muller SH, Seppenwoolde Y, Kwa SL, Boersma LJ, Hart GA, et al Effect of radiotherapy and chemotherapy on pulmonary function after treatment for breast cancer and lymphoma: a follow-up study. J Clin Oncol. 1999;17: 3091-100

32. Delanian S, Balla-Mekias S, Lefaix JL. Striking regression of chronic radiotherapy damage in a clinical trial of combined pentoxifylline and tocopherol. J Clin Oncol. 1999;17:3283-90.

33. Molteni A, Moulder JE, Cohen EF, Ward WF, Fish BL, Taylor JM, et al. Contro of radiation-induced pneumopathy and lung fibrosis by angiotensin-converting enzyme inhibitors and an angiotensin II type 1 receptor blocker. Int J Radiat Biol. 2000;76:523-32.

34. Gasparetto V, Fraccaro C, Tarantini G, Buja P, D'Onofrio A, Yzeiraj E, et al Safety and effectiveness of a selective strategy for coronary artery revascularization before transcatheter aortic valve implantation. Catheter Cardiovasc Interv. 2013;81:376-83.

35. Abdel-Wahab M, Mostafa AE, Geist V, Stocker B, Gordian K, Merten C, et al. Comparison of outcomes in patients having isolated transcatheter aortic valve implantation versus combined with preprocedural percutaneous coronary intervention. Am J Cardiol. 2012;109:581-6. 

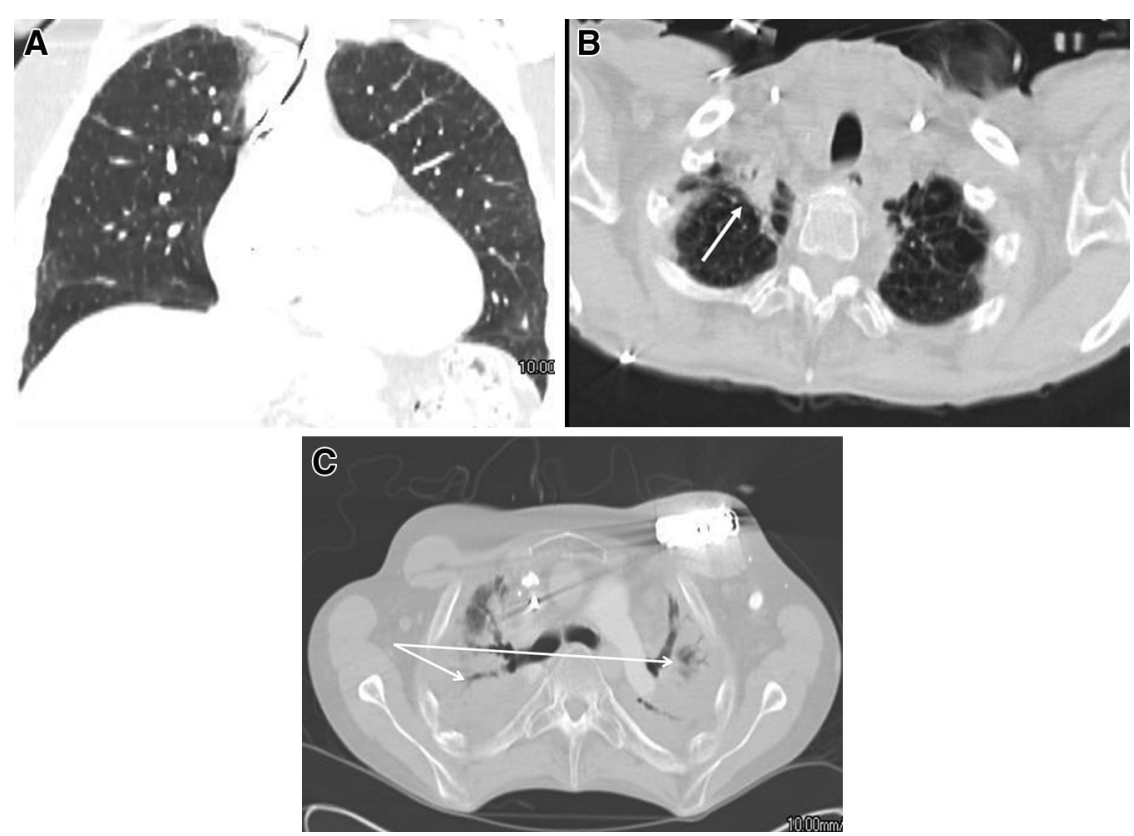

FIGURE E1. MDCT scans in patients with varying degrees of PF: none-minimal (A), moderate (B), and severe (C) (see text for details).

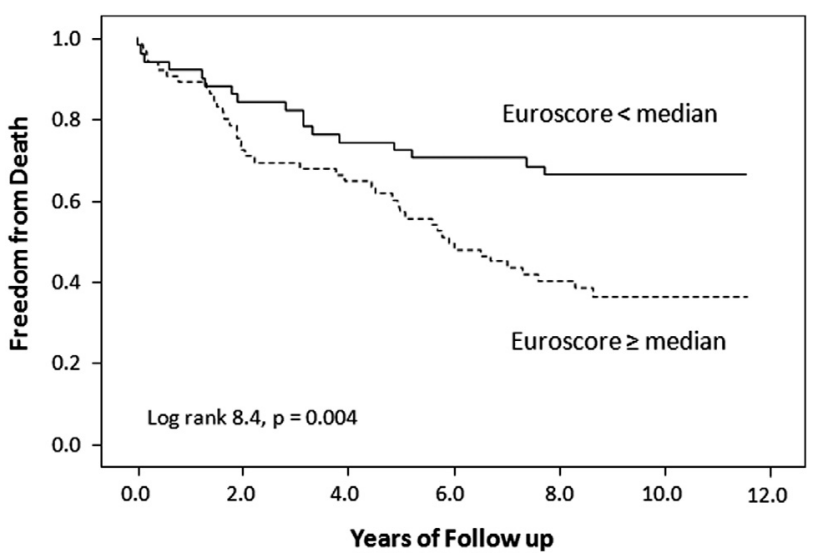

FIGURE E2. Kaplan-Meier curve analysis demonstrating significant differences in long-term mortality in patients with RACD who underwent cardiac surgery, separated on the basis of median euroSCORE $($ median $=8)$. euroSCORE, European System for Cardiac Operative Risk Evaluation.

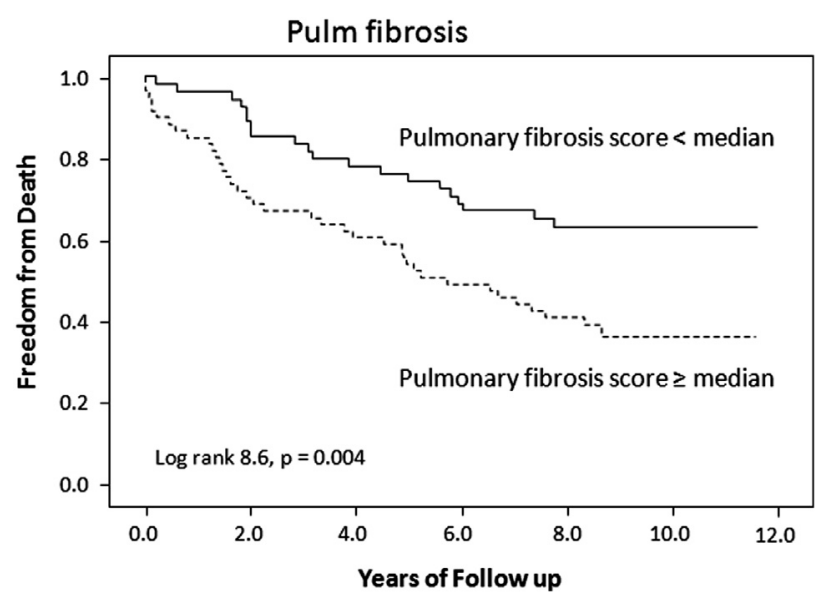

FIGURE E3. Kaplan-Meier curve analysis demonstrating significant differences in long-term mortality in patients with RACD who underwent cardiac surgery, separated on the basis of the median of PF score (median $=3$ ). 
TABLE E1. Postoperative findings in the study population

\begin{tabular}{lc}
\hline \multicolumn{1}{c}{ Variable } & $\mathbf{N}=\mathbf{1 1 7}$ \\
\hline Clinical postoperative characteristics & $17 \pm 40 \mathrm{~d}$ \\
Perioperative length of stay & $5 \pm 10 \mathrm{~d}$ \\
Perioperative intensive care unit length of stay & $19(16 \%)$ \\
Postoperative permanent atrial fibrillation & $12(10 \%)$ \\
Postoperative permanent pacemaker & 0 \\
Postoperative stroke & $45(39 \%)$ \\
Postoperative pulmonary complications (any) & $21(18 \%)$ \\
Postoperative pulmonary complications (major) & \\
Pre-discharge echocardiography & $46 \pm 14$ \\
LV ejection fraction $(\%)$ & $34(29 \%)$ \\
At least mild right ventricular dysfunction & $11(9 \%)$ \\
Mitral regurgitation $(\geq \mathrm{II}+)$ & $3(3 \%)$ \\
Aortic regurgitation $(\geq \mathrm{II}+)$ & $36(31 \%)$ \\
Tricuspid regurgitation $(\geq \mathrm{II}+)$ & $35 \pm 9 \mathrm{~mm} \mathrm{Hg}$ \\
Right ventricular systolic pressure & \\
\hline
\end{tabular}

$L V$, Left ventricular.

TABLE E2. Relevant clinical and imaging characteristics of study population, separated on the basis of pulmonary fibrosis score

\begin{tabular}{|c|c|c|c|}
\hline Variable & PF score $<3(n=55)$ & PF score $\geq 3(n=62)$ & $P$ value \\
\hline Age (y) & $65 \pm 11$ & $62 \pm 15$ & .3 \\
\hline Female gender & $42(76 \%)$ & $41(66 \%)$ & .2 \\
\hline Hypertension & $25(47 \%)$ & $23(37 \%)$ & .2 \\
\hline Diabetes mellitus & $6(11 \%)$ & $13(\%)$ & .13 \\
\hline Prior stroke & $4(8 \%)$ & $6(10 \%)$ & .5 \\
\hline Smoking history & $4(8 \%)$ & $15(24 \%)$ & .02 \\
\hline Proximal obstructive CAD & $27(49 \%)$ & $26(42 \%)$ & .3 \\
\hline Prior open surgery & $9(16 \%)$ & $15(24 \%)$ & .2 \\
\hline $\mathrm{FVC}(\mathrm{mL})$ & $2.5 \pm 0.8$ & $1.8 \pm 0.8$ & .002 \\
\hline$\%$ Predicted FVC & $77 \pm 20$ & $57 \pm 20$ & .001 \\
\hline FEV1 & $1.8 \pm 0.6$ & $1.4 \pm 0.6$ & .004 \\
\hline FEV1/FVC ratio & $0.75 \pm 0.2$ & $0.75 \pm 0.1$ & .9 \\
\hline euroSCORE & $7.1 \pm 3$ & $9 \pm 3$ & .01 \\
\hline \multicolumn{4}{|l|}{ Type of CTS } \\
\hline CABG & $15(27 \%)$ & $5(8 \%)$ & \\
\hline CABG +1 valve & $12(22 \%)$ & $8(13 \%)$ & \\
\hline CABG $+\geq 2$ valve & $10(18 \%)$ & $18(29 \%)$ & \\
\hline 1 valve only & $8(15 \%)$ & $14(23 \%)$ & \\
\hline$\geq 2$ valves & $8(15 \%)$ & $13(21 \%)$ & \\
\hline Others & $2(4 \%)$ & $4(7 \%)$ & .04 \\
\hline In-hospital length of stay (d) & $15 \pm 13$ & $19 \pm 15$ & .2 \\
\hline Intensive care unit stay (d) & $3 \pm 5$ & $6 \pm 5$ & .2 \\
\hline Preoperative LVEF (\%) & $50 \pm 13$ & $49 \pm 13$ & 6 \\
\hline Preoperative RVSP (mm Hg) & $40 \pm 16$ & $45 \pm 13$ & .2 \\
\hline Postoperative RVSP (mm Hg) & $33 \pm 9$ & $36 \pm 10$ & .2 \\
\hline Postoperative RV dysfunction & $5(9 \%)$ & $22(35 \%)$ & .3 \\
\hline Postoperative pulmonary complications (any) & $14(26 \%)$ & $31(50 \%)$ & .005 \\
\hline Postoperative pulmonary complications (major) & $5(9 \%)$ & $16(26 \%)$ & .02 \\
\hline
\end{tabular}

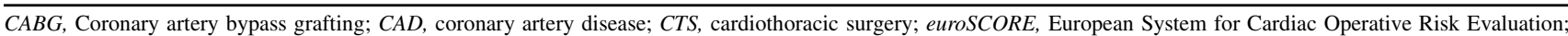
$F E V 1$, forced expiratory volume in 1 second; $F V C$, forced vital capacity; $L V E F$, left ventricular ejection fraction; $P F$, pulmonary fibrosis; $R V$, right ventricular; $R V S P$, right ventricular systolic pressure. 
TABLE E3. Univariable Cox proportional hazard predictors of mortality in the study population

\begin{tabular}{|c|c|c|}
\hline Variable & $\begin{array}{c}\text { Hazard ratio } \\
(\mathbf{9 5} \% \mathbf{C I})\end{array}$ & $\begin{array}{c}P \\
\text { value }\end{array}$ \\
\hline \multicolumn{3}{|l|}{ Preoperative findings } \\
\hline Age & $1.02(0.99-1.02)$ & .08 \\
\hline Gender & $0.74(0.41-1.33)$ & .3 \\
\hline Hypertension & $1.12(0.65-1.94)$ & .7 \\
\hline Diabetes mellitus & $1.21(0.71-2.07)$ & .5 \\
\hline Hyperlipidemia & $0.75(0.40-1.30)$ & .3 \\
\hline Prior stroke & $1.88(0.73-4.81)$ & .12 \\
\hline Proximal obstructive coronary disease & $1.20(0.70-2.06)$ & .5 \\
\hline Implantable defibrillator & $1.02(0.36-2.87)$ & .9 \\
\hline Permanent pacemaker & $1.43(0.77-2.66)$ & .3 \\
\hline Type of prior cancer & $1.05(0.96-1.15)$ & .3 \\
\hline Prior radiotherapy dose for cancer & $0.98(0.95-1.02)$ & .4 \\
\hline Prior open surgery & $0.98(0.53-1.78)$ & .4 \\
\hline Type of cardiac surgery performed & $1.12(0.94-1.34)$ & .2 \\
\hline euroSCORE & $1.14(1.04-1.26)$ & .005 \\
\hline Beta-blockers & $0.49(0.29-0.82)$ & .006 \\
\hline ACE inhibitors & $0.68(0.39-1.22)$ & .2 \\
\hline Aspirin & $0.45(0.26-0.79)$ & .003 \\
\hline Statins & $1.06(0.60-1.85)$ & .8 \\
\hline Serum creatinine & $1.34(0.82-2.17)$ & .09 \\
\hline FEV1 & $0.54(0.22-1.36)$ & .12 \\
\hline $\mathrm{FVC}$ & $0.81(0.49-1.33)$ & .3 \\
\hline$\%$ Predicted FVC & $1.01(0.99-1.04)$ & .3 \\
\hline FEV1/FVC ratio & $0.31(0.17-0.57)$ & .02 \\
\hline LV ejection fraction & $1.00(0.98-1.02)$ & .9 \\
\hline Left atrial area & $1.13(0.74-1.72)$ & .6 \\
\hline LV end-systolic dimension & $0.88(0.58-1.34)$ & .5 \\
\hline Mitral regurgitation & $1.04(0.82-1.32)$ & .7 \\
\hline Aortic regurgitation & $1.08(0.84-1.40)$ & .5 \\
\hline Tricuspid regurgitation & $1.15(0.89-1.49)$ & .3 \\
\hline Right ventricular systolic pressure & $1.01(0.99-1.03)$ & .2 \\
\hline Diastolic dysfunction & $1.03(0.73-1.45)$ & .9 \\
\hline Mitral valve splitability score & $0.99(0.92-1.07)$ & .8 \\
\hline Aortic valve dimensionless index & $0.11(0.02-0.50)$ & $<.001$ \\
\hline PF score on MDCT & $1.11(1.02-1.20)$ & .02 \\
\hline Ascending aortic calcification on MDCT & $1.07(0.84-1.37)$ & .6 \\
\hline \multicolumn{3}{|l|}{ Postoperative findings } \\
\hline LV ejection fraction & $1.02(0.0 .99-1.04)$ & .12 \\
\hline Mitral regurgitation & $1.12(0.67-1.88)$ & .7 \\
\hline Aortic regurgitation & $1.51(0.59-3.86)$ & .3 \\
\hline Tricuspid regurgitation & $1.003(0.75-1.35)$ & .9 \\
\hline Right ventricular systolic pressure & $1.01(0.97-1.06)$ & .4 \\
\hline Right ventricular dysfunction & $0.95(0.50-1.80)$ & .9 \\
\hline Permanent atrial fibrillation & $0.66(0.27-1.62)$ & .3 \\
\hline
\end{tabular}

Bold values represent $P$ values that are significant $(<.05)$. ACE, Angiotensinconverting enzyme; $C I$, confidence interval; euroSCORE, European System for Cardiac Operative Risk Evaluation; $L V$, left ventricular; $F E V I$, forced expiratory volume in 1 second; $F V C$, forced vital capacity; $M D C T$, multidetector chest computed tomography; $P F$, pulmonary fibrosis. 